\title{
CURVAS DE DISTRIBUIÇÃO DE EFLUENTES DO ÍON NITRATO EM AMOSTRAS DE SOLO DEFORMADAS E INDEFORMADAS ${ }^{1}$
}

\section{PAULO ROSSI ${ }^{2}$, JARBAS H. MIRANDA ${ }^{3}$, SÉRGIO N. DUARTE $^{4}$}

RESUMO: Devido à grande importância em se avaliar o destino e o transporte de íons no solo, o presente trabalho teve o objetivo de obter os parâmetros de transporte do nitrato no solo, como a velocidade da água nos poros (v), o fator de retardamento $(R)$, a dispersividade $(\lambda)$ e o coeficiente de dispersão (D), em solos de diferentes texturas e em amostras deformadas e indeformadas. $\mathrm{O}$ ensaio foi conduzido empregando as amostras deformadas e indeformadas oriundas de dois perfis distintos de solos, coletadas à profundidade de $0-20 \mathrm{~cm}$, com aplicação de solução de nitrato de cálcio contendo $50 \mathrm{mg} \mathrm{L}^{-1}$ de $\mathrm{NO}_{3}^{-}$. Após a obtenção dos parâmetros de transporte, ajustados pelo programa computacional CXTFIT, notou-se que as curvas de efluentes preparadas com solos a partir de amostra deformada superestimaram os valores dos parâmetros avaliados, com exceção da dispersividade, quando comparados à amostra indeformada, para os dois tipos de solo.

PALAVRAS-CHAVE: dinâmica de solutos, amostras de solo, parâmetros de transporte.

\section{BREAKTHROUGH CURVES OF NITRATE ION USING DEFORMED AND NON DEFORMED SOIL SAMPLES}

\begin{abstract}
There is a great importance to quantify the trace and the chemical elements transport in soil. This work had as objective to obtain the transport parameters of the nitrate ion in soil (pore water velocity $(\mathrm{v})$, retardation factor $(\mathrm{R})$, dispersivity $(\lambda)$ and the dispersion coefficient (D)) in different textures soils, mainly, under different sampling forms (deformed and non deformed). The research was carried out under two samplings forms, mentioned previously, by application of 50 $\mathrm{mg} \mathrm{L}^{-1}$ of $\mathrm{NO}_{3}{ }^{-}$in two different soils profiles at a depth of 0-20 $\mathrm{cm}$. The breakthrough curves was made by two forms: traditional methodology (TFSA) and the technique with non deformed sample developed during the research period. The results showed that the transport parameters fitted by the computational program CXTFIT, with deformed sampling, overestimated the parameters values, with exception of dispersivity, when compared to the non deformed sampling, for both soil types.
\end{abstract}

KEYWORDS: solute dynamic, soil sampling, transport parameters.

\section{INTRODUÇÃO}

Os recursos hídricos, que, no passado, eram considerados fartos, hoje são limitados e comprometidos em virtude da alta poluição causada pelo aumento da produção de esgotos urbanos, aumento das áreas de aterros sanitários e uso indiscriminado de defensivos agrícolas e, às vezes, de fertilizantes, devido à baixa fertilidade dos solos tropicais (BETTIOL et al., 2000).

Os Latossolos e os Argissolos são solos altamente intemperizados, que predominam no território brasileiro, e são de grande relevância na América Latina, pois estão ocupados por extensas áreas cultivadas.

Avaliando-se as características desses solos, nota-se baixa capacidade de troca de íons, cargas variáveis ou dependentes do $\mathrm{pH}$, alta acidez, boa porosidade e alta permeabilidade, características

\footnotetext{
${ }^{1}$ Pesquisa de Iniciação Científica - CNPq.

${ }^{2}$ Graduando em Engenharia Agronômica, Departamento de Ciências Exatas, Escola Superior de Agricultura "Luiz de Queiroz", ESALQ/USP, Av. Pádua Dias, 11, Piracicaba - SP, Fone: (0XX19) 3429.4283, parossi@ esalq.usp.br

${ }^{3}$ Prof. Dr., Departamento de Ciências Exatas, ESALQ/USP, jhmirand@esalq.usp.br

${ }^{4}$ Prof. Dr., Departamento de Engenharia Rural, ESALQ/USP, snduarte@ carpa.ciagri.usp.br

Recebido pelo Conselho Editorial em: 30-4-2006
}

Aprovado pelo Conselho Editorial em: 20-8-2007 
que maximizam as perdas de nutrientes do solo por lixiviação, principalmente dos que se apresentam sob a forma aniônica, como o nitrato ( $\mathrm{NO}_{3}^{-}$) (FONTES et al., 2001). PARFITT (1978), citado por RAIJ (1998), indica a seguinte afinidade de ânions com a superfície de óxidos de ferro e alumínio hidratados: fosfato $>$ molibdato $>$ fluoreto $>$ sulfato $>$ cloreto $>$ nitrato. Portanto, a tendência é que praticamente todo o nitrato adicionado ao solo fique dissolvido na solução, sendo parte absorvido pelo sistema radicular das plantas, cerca de $60 \%$, e os $40 \%$ restantes sujeitos aos processos de lixiviação abaixo da zona radicular e desnitrificação (PADOVESE, 1988).

A lixiviação de nutrientes varia com os atributos físicos do solo, como textura, estrutura, profundidade do perfil e, principalmente, porosidade. Entre os atributos químicos que afetam a lixiviação, estão a capacidade de retenção de íons e o pH (SANTOS et al., 2002).

O nitrato, em particular, pode alcançar os lençóis freáticos e cursos de água, causando enfermidades pelo consumo de água contaminada (cianose infantil ou metaemoglobinemia e câncer no estômago) e danos ambientais, tais como a eutrofização (BURT, 1993). Quanto à mobilidade do $\mathrm{NO}_{3}^{-}$, pode-se dizer que o fluxo de massa (advecção) é o único responsável pelo seu movimento no perfil do solo, dependendo estritamente do fluxo de água que arrasta os nutrientes (PADOVESE, 1988). Desse modo, o movimento desse íon no solo será afetado diretamente pelos fatores que modificam o movimento da água no solo, como a porosidade e a estrutura.

Nesse contexto, segundo BORGES JÚNIOR (2002), a preocupação com o comportamento de determinados produtos químicos no subsolo tem motivado os pesquisadores a desenvolver modelos teóricos, com o objetivo de descrever os processos físicos envolvidos no transporte de solutos no perfil do solo.

Pelo fato de se lidar com o movimento simultâneo da água e do soluto no solo, considera-se que o transporte de solutos é consequiência da convecção, ou seja, do fluxo de massa (movimento laminar ou viscoso da solução do solo) e da difusão (movimentação térmica dos solutos dentro da solução). O entendimento desses dois componentes do processo de transporte, que ocorrem simultaneamente, é fundamental para o estabelecimento de práticas de manejo para o controle do movimento de íons no solo (BRESLER, 1981). Os estudos da dinâmica dos solutos não proporcionam somente um meio de determinação do fluxo no solo, mas devem dar uma explicação física do fenômeno que ocorre na percolação, na troca e adsorção de íons, para o movimento de íons de fertilizantes minerais e de outros sais (NIELSEN, 1961).

Para a compreensão desse fenômeno, calculam-se os parâmetros de transporte, como a velocidade da água nos poros (v), o fator de retardamento (R), o coeficiente de dispersão (D) e a dispersividade $(\lambda)$. O método mais comum é o ajuste dos modelos teóricos a dados experimentais de laboratório (curvas de eluição), empregando-se programas computacionais. Dentre esses programas, pode-se destacar o modelo CXTFIT (TORIDE, 1999), de ampla utilização, aplicado para a estimativa dos parâmetros a partir de concentrações observadas (problema inverso) ou para prever a concentração de solutos (problema direto), usando equações de convecção-dispersão como modelo de transporte, utilizando um método de otimização (minimização da soma dos desvios) não-linear para a obtenção dos parâmetros. Assim, teve-se o objetivo de obter os parâmetros de transporte para o ânion nitrato em amostras de solo deformadas e indeformadas, e avaliar a influência do processo de amostragem no deslocamento do ânion no solo, utilizando-se do modelo CXTFIT.

\section{MATERIAL E MÉTODOS}

O experimento foi conduzido no Laboratório de Física de Solos do Departamento de Engenharia Rural - ESALQ/USP. A coleta das amostras de solo deformadas e indeformadas foi feita em dois solos: um Latossolo Vermelho-Amarelo, textura média (Solo 1), proveniente de Piracicaba - SP, e um Latossolo Vermelho-Amarelo, textura argilosa (Solo 2), proveniente de 
Jaguariúna - SP, os quais foram classificados de acordo com o Sistema Brasileiro de Classificação de Solos (EMBRAPA, 1999).

Foram determinados os seguintes atributos físico-hídricos dos solos: condutividade hidráulica do solo saturado (Ko) (Método do Permeâmetro de Carga Constante), densidade do solo $\left(\mathrm{D}_{\mathrm{s}}\right)$, densidade de partículas $\left(\mathrm{D}_{\mathrm{p}}\right)$ (Método do Picnômetro), porosidade $(\alpha)$ e textura (areia, silte e argila) (Método de Bouyoucos) (Tabela 1).

TABELA 1. Atributos físico-hídricos dos solos.

\begin{tabular}{ccccccccc}
\hline LVA Textura & Areia & Silte & Argila & $\mathrm{d}_{\mathrm{s}}$ & $\mathrm{d}_{\mathrm{p}}$ & $\alpha$ & $\mathrm{K}_{0}{ }^{\mathrm{a}}$ & $\mathrm{K}_{0}{ }^{\mathrm{b}}$ \\
\hline & $-----------\mathrm{g} \mathrm{kg}^{-1}$ & --------- & $------\mathrm{kg} \mathrm{dm}^{-3}-----$ & $\%$ & $-----\mathrm{cm} \mathrm{h}^{-1}------$ \\
Média (Solo 1) & 682 & 100 & 218 & 1,56 & 2,65 & 41,13 & 18,94 & 2,48 \\
Argilosa (Solo 2) & 153 & 254 & 593 & 1,31 & 2,46 & 46,75 & 4,10 & 1,70 \\
\hline
\end{tabular}

$\mathrm{d}_{\mathrm{s}}$ e $\mathrm{d}_{\mathrm{p}}$ - densidade do solo e de partículas; $\alpha$ - porosidade; $\mathrm{K}_{0}{ }^{\mathrm{a}} \mathrm{e} \mathrm{K}_{0}^{\mathrm{b}}$ - condutividade hidráulica da amostra deformada $\mathrm{e}$ indeformada.

\section{Preenchimento das colunas}

O preenchimento das colunas de solo, para a obtenção das curvas de distribuição de efluente, foi feito de duas formas. O primeiro empregando-se amostras deformadas de solo, coletando-se em perfis característicos, à profundidade de $20 \mathrm{~cm}$ da superfície. No laboratório, realizou-se o preparo da amostra, utilizando-se da metodologia TFSA (terra fina seca ao ar). Após esse processo, preencheram-se as colunas com os respectivos solos, as quais foram utilizadas para a obtenção das curvas de distribuição de efluentes, confeccionadas com tubos de irrigação de PVC de $7 \mathrm{~cm}$ de diâmetro interno e $25 \mathrm{~cm}$ de comprimento, com uma de suas extremidades recoberta com tela filtrante presa ao tubo por tela metálica e luva de PVC de 7,5 cm de diâmetro.

Para a coleta das amostras indeformadas de solo, foi necessária, para cada tipo de solo, a coleta de monolitos com secção quadrada de $15 \mathrm{~cm}$ e $25 \mathrm{~cm}$ de altura, a partir da superfície do solo (Figura 1a).

Os monolitos foram retirados do perfil de solo, de modo a evitar perturbações em sua estrutura original. Em seguida, no próprio local de sua retirada, realizou-se uma preparação prévia, moldando-se um cilindro, com as dimensões de $10 \mathrm{~cm}$ de diâmetro e $25 \mathrm{~cm}$ de altura (Figura 1b). Essa pré-amostra cilíndrica foi transportada ao laboratório, protegida dentro de um tubo de PVC para evitar perturbações em sua estrutura. No laboratório, a amostra passou por uma etapa de preparo, para que, ao final, apresentasse as seguintes dimensões: $7 \mathrm{~cm}$ de diâmetro e $20 \mathrm{~cm}$ de altura a partir da superfície de cada bloco de solo (Figura 1c).

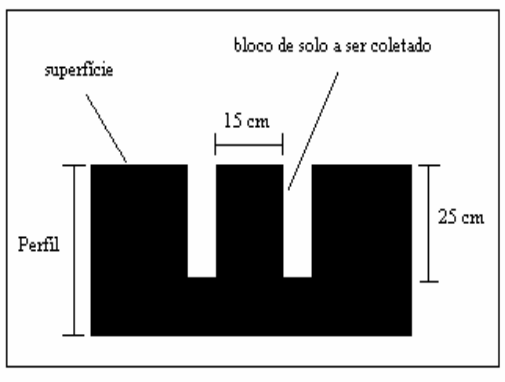

(a)

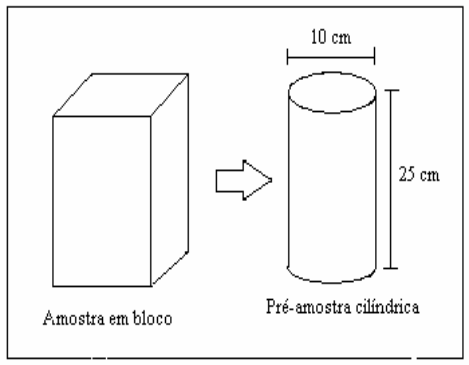

(b)

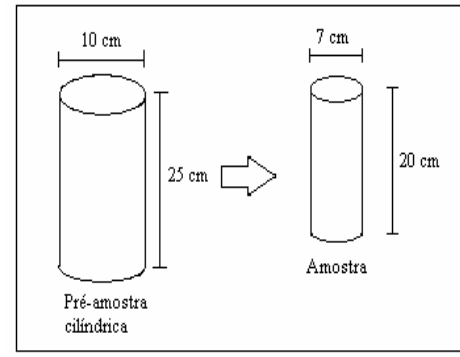

(c)

FIGURA 1. Esquema da escavação e da retirada do monolito (a); raspagem do monolito e retirada de pré-amostra cilíndrica (b), e retrabalho da pré-amostra cilíndrica e obtenção da amostra cilíndrica final (c). 
Essa amostra foi introduzida em um tubo de PVC, seccionado pela metade, no sentido do comprimento, com 7,2 cm de diâmetro interno e $20 \mathrm{~cm}$ de comprimento. Para melhor acomodação entre a amostra e a parede do tubo, foram utilizados dois tipos de adesivos, com o objetivo de evitar possíveis fluxos preferenciais durante o processo de passagem da solução através da coluna de solo. Nessa etapa, primeiramente impermeabilizou-se toda a lateral da amostra cilíndrica de solo com o adesivo PVA e, após a secagem, passou-se um filme do adesivo de silicone, introduzindo-se a amostra no tubo de PVC (Figura 2).

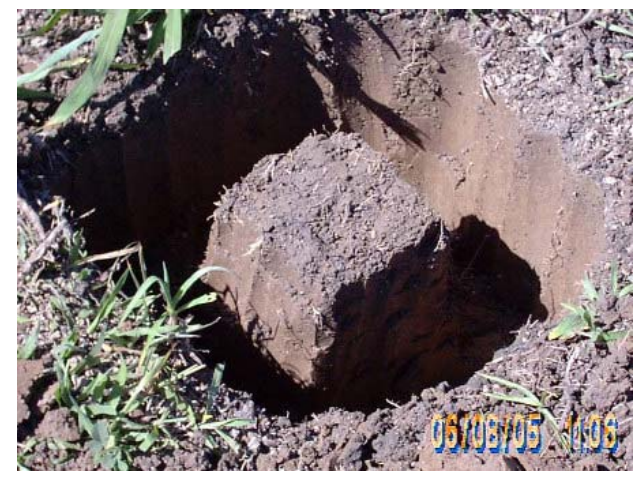

(a)

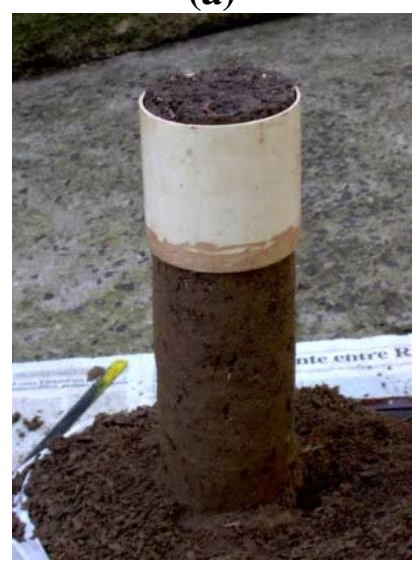

(c)

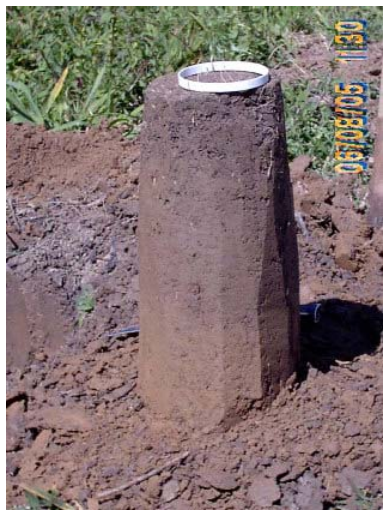

(b)

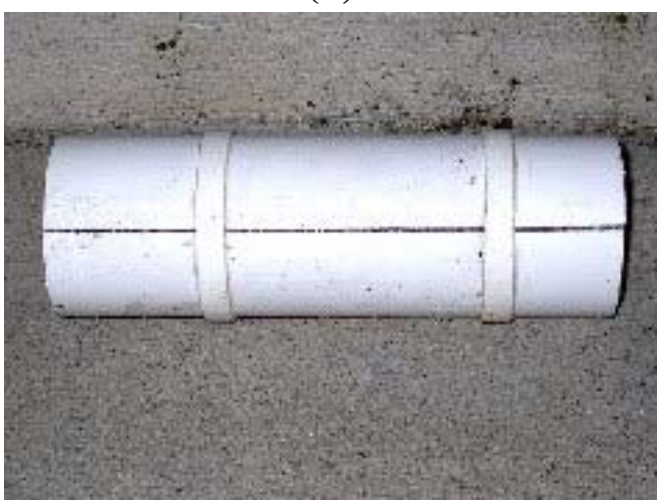

(d)

FIGURA 2. Detalhe da escavação (a); início do preparo da pré-amostra (b); início do preparo da amostra cilíndrica final (c), e detalhe da amostra após ser colada no tubo de PVC (d).

\section{Obtenção dos parâmetros de transporte}

Para a obtenção dos parâmetros de transporte do nitrato, nas amostras deformadas e nas indeformadas, montou-se um esquema em laboratório (Figura 3).

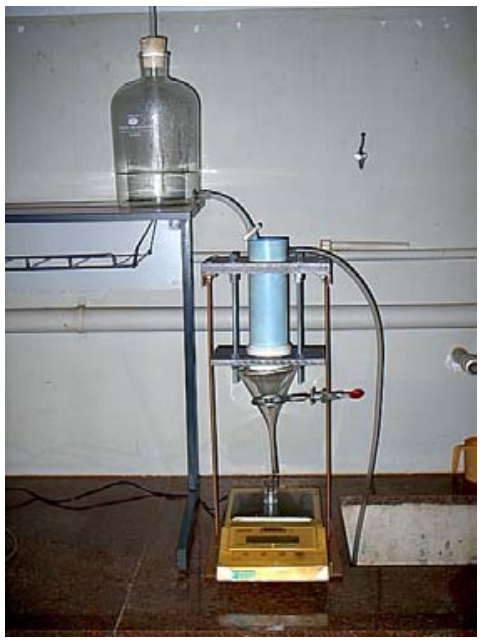

FIGURA 3. Esquema da aparelhagem de ensaio. 
Para que o teste fosse iniciado, primeiramente saturou-se por capilaridade a coluna com água destilada, processo esse realizado de forma lenta, no qual a coluna foi colocada dentro de um balde e, por gotejamento, a água foi adicionada até atingir altura aproximada de $2 / 3$ da coluna (Figura 4a). Em seguida, deixou-se o conjunto em repouso durante 48 horas até completa saturação e, após esse prazo, deu-se início ao teste, deixando-se passar água destilada através da coluna de solo por um período de $96 \mathrm{~h}$, para que se tivesse garantia de que os íons nitrato presentes na solução do solo, que preenchia a coluna, fossem retirados (Figura $4 b$ ).

Atingido o fluxo constante, que foi alcançado pela manutenção de lâmina constante de $1 \mathrm{~cm}$ (controlada por um dreno), na parte superior da coluna, substituiu-se o fornecimento de água por solução de $\mathrm{Ca}\left(\mathrm{NO}_{3}\right)_{2} 4 \mathrm{H}_{2} \mathrm{O}$, a uma concentração de $50 \mathrm{mg} \mathrm{L}^{-1}$ de $\mathrm{NO}_{3}^{-}$. A partir desse ponto, iniciou-se a coleta dos volumes da solução que atravessaram a coluna de solo e a cronometragem do ensaio (Figura 4c) (MIRANDA, 2001).

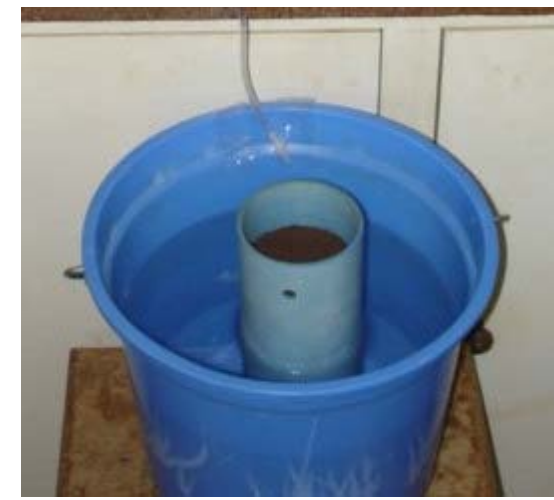

(a)

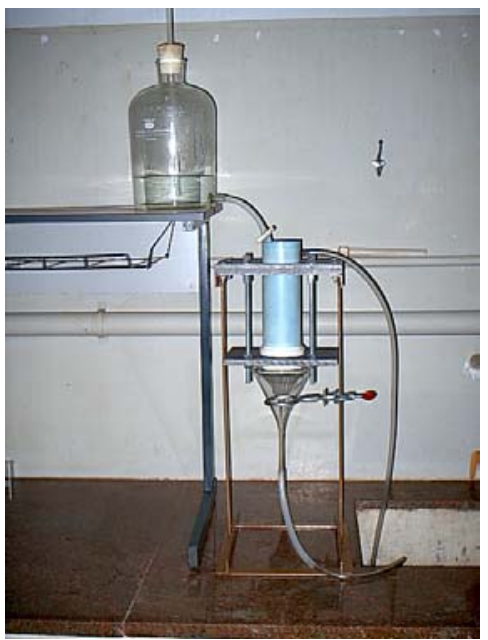

(b)

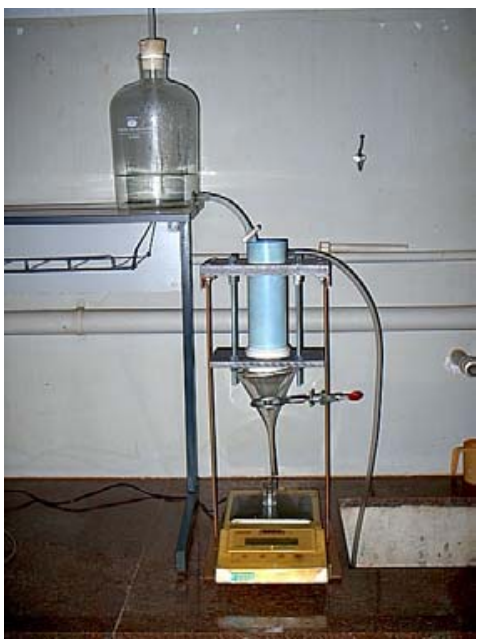

(c)

FIGURA 4. Etapa de saturação da amostra (a); lixiviação da coluna (b), e coleta dos efluentes (c).

Os volumes coletados dos efluentes foram de $15 \mathrm{~mL}$ e definidos em função do volume de poros, cujos valores estão em função do volume total da coluna $\left(769,0 \mathrm{~cm}^{3}\right)$ e da porosidade do solo em questão, calculado pela eq.(1):

$$
1 \mathrm{VP}=\alpha \mathrm{V}
$$

em que,

VP - volume de poros, $\mathrm{cm}^{3}$

$\alpha$ - porosidade do solo em questão, $\mathrm{cm}^{3} \mathrm{~cm}^{-3}$, e

$\mathrm{V}$ - volume da coluna, $\mathrm{cm}^{3}$.

Como o teste foi realizado em função da concentração relativa do efluente $(\mathrm{C} / \mathrm{Co})(\mathrm{C}=$ concentração coletada do efluente (ppm) e $C_{0}=$ concentração inicial da solução (ppm)), atingindose o valor de $100 \%$ de solução de aplicação, o teste foi encerrado, e as amostras submetidas à análise em laboratório, utilizando-se para isso do equipamento FIA - Flow Injection Analysis. Apenas para auxiliar no monitoramento da elaboração da curva de distribuição de efluentes, utilizou-se de um equipamento de teste rápido (Horiba). Em seguida, para determinar os parâmetros de transporte (velocidade da água nos poros (v), coeficiente de dispersão (D), dispersividade $(\lambda)$ e fator de retardamento $(\mathrm{R})$ ) relativos a cada tipo de solo, mediante ajuste matemático, utilizou-se do modelo CXTFIT, desenvolvido pelo U.S. Salinity Laboratory - USDA Riverside-CA, versão 2.1 (atualizado em novembro de 1998), escrito na linguagem de programação FORTRAN. 


\section{RESULTADOS E DISCUSSÃO}

Os resultados obtidos para os valores dos parâmetros de transporte do nitrato (velocidade da água nos poros (v), coeficiente de dispersão (D), dispersividade $(\lambda)$ e fator de retardamento (R)), mediante o bom ajuste das curvas de distribuição de efluentes, relativos às amostras deformadas e indeformadas dos solos LVA textura média (Solo 1) e LVA argiloso (solo 2), evidenciaram efeito da forma de preenchimento das colunas. Notou-se que houve redução expressiva da condutividade hidráulica, comprovada pelo parâmetro velocidade da água nos poros (v), entre as amostras, e isso influenciou significativamente na dinâmica do soluto: as amostras deformadas apresentaram fator de retardamento maior do íon nitrato, comparadas aos mesmos solos, às amostras indeformadas (Tabela 2).

Isso, de certa forma, evidencia o efeito de repulsão do solo, com o predomínio de cargas negativas ao nitrato. Além disso, esse fenômeno certamente esteve relacionado à forma de preenchimento das colunas, pois, nas amostras deformadas, são eliminadas as raízes e desagrega-se o solo, afetando a sua macroporosidade. Portanto, quando se preenche uma coluna de solo com essas características, altera-se a densidade do solo em relação às condições naturais. Analisando-se o parâmetro dispersividade $(\lambda)$ (Tabela 2), percebe-se que o íon nitrato percorre praticamente o dobro da distância na amostra indeformada em comparação à deformada, sendo assim lixiviado do solo com maior rapidez. Além do já mencionado, há a eluviação de partículas coloidais durante o processo de lavagem com água destilada em função da desestruturação do solo, evidenciado pela coloração do efluente coletado.

TABELA 2. Parâmetros de transporte do nitrato (amostras deformadas e indeformadas) dos solos 1 e 2: velocidade da água nos poros (v), coeficiente de dispersão (D), fator de retardamento $(\mathrm{R})$ e dispersividade $(\lambda)$.

\begin{tabular}{lccccc}
\hline \multirow{2}{*}{ Tipo de Amostra } & \multirow{2}{*}{ Solo } & \multicolumn{4}{c}{ Parâmetros de Transporte do Nitrato } \\
\cline { 2 - 6 } & & $\mathrm{v}\left(\mathrm{cm} \mathrm{min}^{-1}\right)$ & $\mathrm{D}\left(\mathrm{cm}^{2} \mathrm{~min}^{-1}\right)$ & $\mathrm{R}$ & $\lambda(\mathrm{cm})$ \\
\hline \multirow{2}{*}{ Deformada } & 1 & 0,8175 & 0,3731 & 1,2070 & 0,4564 \\
& 2 & 0,1822 & 0,4460 & 0,9322 & 2,4479 \\
\hline \multirow{2}{*}{ Indeformada } & 1 & 0,0936 & 0,1561 & 0,8102 & 1,6677 \\
& 2 & 0,0753 & 0,3488 & 0,6333 & 4,6303 \\
\hline
\end{tabular}

Desse modo, a amostra indeformada é mais adequada pelo fato de representar mais fielmente as condições naturais. Com base nas análises das curvas de distribuição de efluentes obtidas, percebe-se que a adsorção do íon nitrato é muito menor no Solo 2 em relação ao Solo 1, fato esse devido também ao maior número de cargas negativas do Solo 2 em relação ao Solo 1, em ambas as formas de amostragem e em ambas as amostras (deformadas e indeformadas) (Figura 5). 


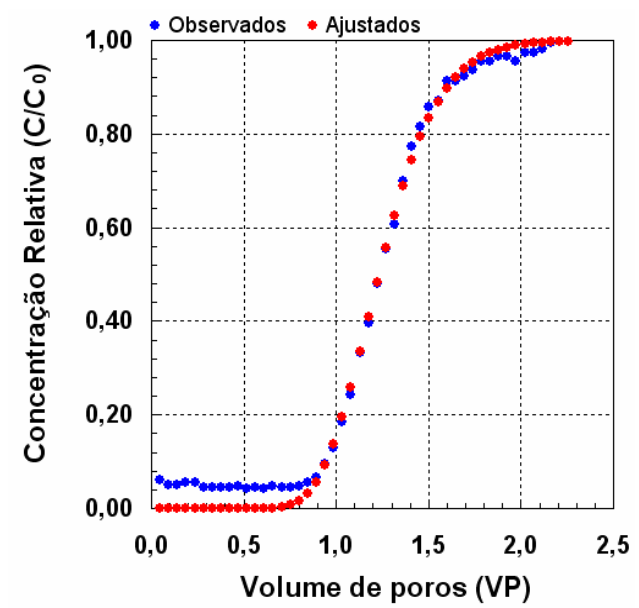

(a)

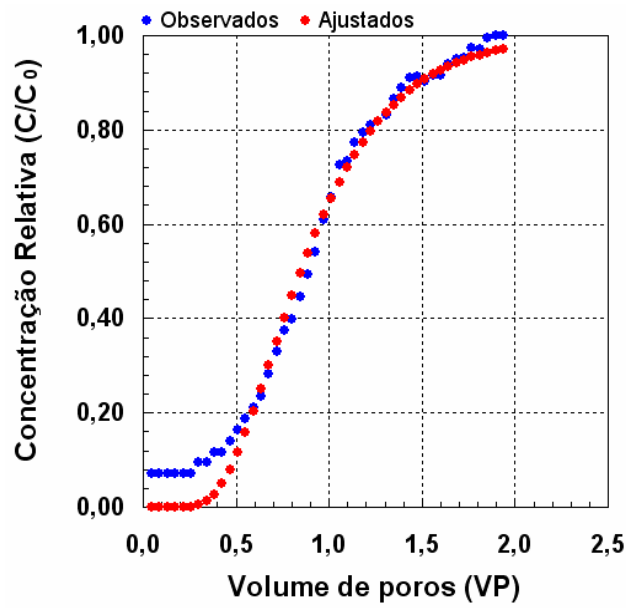

(c)

FIGURA 5. Curva de distribuição do efluente para o solo 1 (amostra deformada (a) e indeformada (b)) e para o solo 2 (amostra deformada (c) e amostra indeformada (d)).

\section{CONCLUSÕES}

O preenchimento da coluna com amostra de solo deformada não foi representativo para nenhum dos parâmetros de transporte do íon nitrato, considerando-se, assim, como situação ideal o solo estruturado.

\section{REFERENCIAS}

BETTIOL,W.; CAMARGO, O.A. Impacto ambiental do uso agrícola do lodo de esgoto. Jaguariúna: Embrapa Meio Ambiente, 2000. 312 p.

BORGES JÚNIOR, J.C.; FERREIRA, P.A. Programa Computacional para cálculo de parâmetros do transporte de solutos em deslocamento de fluidos miscíveis. In: CONGRESSO BRASILEIRO DE ENGENHARIA AGRÍCOLA, 31., 2002, Salvador. Anais...Salvador: SBEA, 2002. 1 CDROM.

BRESLER, E. Convective and pore scale dispersive solute transport in unsaturated heterogeneous fields. Water Resources Research, Washington, v.37, n.6, p.1.683-93, 1981.

BURT, T.P.; HEATHWAITE, A.L.; TRUDGILL, S.T. Nitrate process, patterns and management. Chichester: John Wiley, 1993. cap.15, p.404-8

EMBRAPA. EMPRESA BRASILEIRA DE PESQUISA AGROPECUÁRIA. Sistema brasileiro de classificação de solos. Rio de Janeiro, 1999. 412 p. 
FONTES, M.P.F.; CAMARGO, O.A.; SPOSITO, G. Eletroquímica das partículas coloidais e sua relação com a mineralogia de solos altamente intemperizados. Scientia Agricola, Piracicaba, v.58, n.3, p.627-46, 2001.

MIRANDA, J.H. Modelo para simulação da dinâmica do nitrato em colunas verticais de solo nãosaturado. 2001. 79 f. Tese (Doutorado em Irrigação e Drenagem) - Escola Superior de Agricultura "Luiz de Queiroz", Universidade de São Paulo, Piracicaba, 2001.

NIELSEN, D.R.; BIGGAR, J.W. Miscible displacement in soils: I. Experimental Information. Soil Science Society of America, Madison, v.25, n.1, p.1-5, 1961.

PADOVESE, P.P. Movimento e perdas de nitrogênio e potássio num solo com cana-de-açúcar (Saccharum ssp.). 1988. 119 f. Dissertação (Mestrado em Agrometeorologia) - Escola Superior de Agricultura "Luiz de Queiroz”, Universidade de São Paulo, Piracicaba, 1988.

RAIJ, B.V. Gesso agrícola na melhoria do ambiente radicular no solo. São Paulo: ANDA Associação Nacional para Difusão de Adubos e Corretivos Agrícolas, 1998. 88 p.

SANTOS, A.B.; FAGERIA, N.K.; ZIMMERMANN, F.J.P. Atributos químicos do solo afetado pelo manejo da água e do fertilizante potássico na cultura de arroz irrigado. Revista Brasileira de Engenharia Agrícola e Ambiental, Campinas Grande, v.6, n.1, p.12-16, 2002.

TORIDE, N.; LEIJ, F.J.; GENUCHTEN, M.T. van. The CXTFIT Code for Estimating Transport Parameters from Laboratory or Field Tracer Experiments, Version 2.1. Riverside: USDA, Salinity Laboratory, 1999. 119 p. (Research Report, 137) 